\title{
Physiological properties of enkephalin-containing neurons in the spinal dorsal horn visualized by expression of green fluorescent protein in BAC transgenic mice
}

\author{
Teruyuki Fukushima ${ }^{1 *}$, Masayuki Tsuda ${ }^{1}$, Takefumi Kofuji ${ }^{2}$ and Yuuichi Hori ${ }^{1}$
}

\begin{abstract}
Background: Enkephalins are endogenous opiates that are assumed to modulate nociceptive information by mediating synaptic transmission in the central nervous system, including the spinal dorsal horn.

Results: To develop a new tool for the identification of in vitro enkephalinergic neurons and to analyze enkephalin promoter activity, we generated transgenic mice for a bacterial artificial chromosome (BAC). Enkephalinergic neurons from these mice expressed enhanced green fluorescent protein (eGFP) under the control of the preproenkephalin (PPE) gene (penk1) promoter. eGFP-positive neurons were distributed throughout the gray matter of the spinal cord, and were primarily observed in laminae I-II and V-VII, in a pattern similar to the distribution pattern of enkephalin-containing neurons. Double immunostaining analysis using anti-enkephalin and anti-eGFP antibodies showed that all eGFP-expressing neurons contained enkephalin. Incubation in the presence of forskolin, an activator of adenylate cyclase, increased the number of eGFP-positive neurons. These results indicate that eGFP expression is controlled by the penk1 promoter, which contains cyclic AMP-responsive elements. Sections obtained from sciatic nerve-ligated mice exhibited increased eGFP-positive neurons on the ipsilateral (nerve-ligated side) compared with the contralateral (non-ligated side). These data indicate that PPE expression is affected by peripheral nerve injury. Additionally, single-neuron RT-PCR analysis showed that several eGFP positive-neurons in laminae I-II expressed glutamate decarboxylase 67 mRNA and that some expressed serotonin type 3 receptors.

Conclusions: These results suggest that eGFP-positive neurons in laminae I-II coexpress enkephalin and $\gamma$ aminobutyric acid (GABA), and are activated by forskolin and in conditions of nerve injury. The penk1-eGFP BAC transgenic mouse contributes to the further characterization of enkephalinergic neurons in the transmission and modulation of nociceptive information.
\end{abstract}

\section{Background}

Enkephalin-containing neurons are found in several areas of the central nervous system, including the dorsal horn of the spinal cord [1-3], where they play an important role in the transmission and modulation of nociceptive information [4].

The analgesic effect of intrathecally administered 5hydroxytryptamine $(5-\mathrm{HT})$ type $3\left(5-\mathrm{HT}_{3}\right)$ receptor

\footnotetext{
* Correspondence: tfukushi@dokkyomed.ac.jp

'Department of Physiology and Biological Information, Dokkyo Medical University, School of Medicine, Kitakobayashi 880, Mibu, Tochigi 321-0293, Japan

Full list of author information is available at the end of the article
}

agonist 2-methyl-serotonin is attenuated by the opioid antagonist naloxone [5,6], suggesting that endogenous opiate-like substances may be involved in 5-HT-induced antinociception. Enkephalin-containing neurons in the superficial dorsal horn $(\mathrm{SDH})$ of the spinal trigeminal nucleus in rats are innervated by 5 -HT-containing fibers [7-9]. Furthermore, we have reported that enkephalinergic neurons express $5-\mathrm{HT}_{3}$ receptors in the dorsal horn of the spinal cord [10]. These findings suggest that some antinociception is elicited by activation of $5-\mathrm{HT}_{3}$ receptors in spinal dorsal horn neurons containing enkephalin.

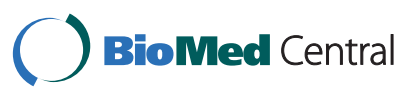


Immunohistochemical investigations showed that several SDH neurons contain both enkephalin and $\gamma$-aminobutyric acid (GABA) [11-13]. We showed that activation of $5-\mathrm{HT}_{3}$ receptors facilitates the release of GABA from some interneurons in SDH [14]. Thus, the antinociceptive action of 5-HT may depend on the release of both enkephalin and GABA by SDH interneurons that express $5-\mathrm{HT}_{3}$ receptors.

The preproenkephalin (PPE) promoter contains cyclic AMP (cAMP)-responsive elements, and the expression of enkephalin is controlled by cAMP [15]. We observed that forskolin, an activator of adenylate cyclase (AC), affects the expression of enkephalin-green fluorescent protein (GFP) fluorescence in neurons in mouse spinal cord sections transfected with the GFP gene driven by the PPE promoter [16].

Peripheral nerve injury and tissue inflammation often induce a state of abnormal pain known as neuropathic pain, which includes hyperalgesia and allodynia [17]. Chronic constriction injury (CCI) of the sciatic nerve increases Met-enkephalin immunoreactivity in the spinal cord [18]. Increases in enkephalin have also been described in spinal cord injury [19], polyarthritis [20], electrical stimulation [21], and various other preparations, using immunocytochemistry and in situ hybridization histochemistry to detect changes in enkephalin. To develop a new, more efficient, tool for the analysis of enkephalin promoter activity and characterization of enkephalinergic neurons, we generated a bacterial artificial chromosome (BAC) transgenic mouse in which enhanced green fluorescent protein (eGFP) is expressed in enkephalinergic neurons under the control of the PPE gene (penk1) promoter.

\section{Results}

eGFP expression and endogenous enkephalin expression Figure 1A shows an overview of the distribution of eGFP-positive neurons in the lumbar spinal cord, showing a dense distribution of eGFP-positive neurons in SDH and infrequent eGFP-positive neurons sparsely distributed throughout the deep dorsal horn and central canal. The observed distribution of eGFP-positive neurons is similar to that of a previous report demonstrating that many interneuronal somata in the substantia gelatinosa show enkephalin immunoreactivity $[3,8,22]$.

To assess the correlation of eGFP fluorescence with endogenous enkephalin expression in SDH, we performed double immunostaining with anti-eGFP and anti-enkephalin antibodies. Figure 1(B-D) shows representative double-staining immunohistochemical images for eGFP and enkephalin. In 26 sections randomly selected from three mice, we determined that, of the 1550 lamina II neurons immunostained for eGFP, 1544 (99.6\%) were also immunolabeled for enkephalin. In the same 26 sections, 1552 lamina II neurons were immunostained for enkephalin, and 1544 (99.5\%) were immunolabeled for eGFP.

\section{Increased number of eGFP-positive neurons in the presence of forskolin}

The expression of enkephalin is controlled by cAMP, owing to the cAMP-responsive elements contained within the PPE promoter [23]. We examined whether our penk1-eGFP BAC transgenic mouse was useful for analyzing the effect of forskolin, an activator of $\mathrm{AC}$, on the PPE promoter. To evaluate the effect of forskolin treatment, transverse spinal sections were exposed to a 60 minutes bath application of forskolin, and the number of eGFP-positive neurons was counted at 5-minute intervals. The number of eGFP-positive neurons in sections significantly increased compared to the control when forskolin was added to the Krebs solution, while the number of control (without forskolin treatment) decreased gradually with fading of eGFP fluorescence upon exposure to ultraviolet (UV) light, as illustrated in Figure $2 \mathrm{C}$. The effect of forskolin was statistically significant (ANOVA, $P<0.05$; Figure $2 \mathrm{C}$ ) in a comparison between forskolin treatment $(n=7)$ and the control ( $n$ $=7$ ). Percentage increase in the ratio of the number of eGFP-positive neurons with forskolin treatment to the number of control neurons was $21.8 \% \pm 7.5 \%$ after $1 \mathrm{~h}$ of forskolin treatment (filled square in Figure 2C). This increase in eGFP-positive neurons may reflect an increase in the expression level of enkephalin above the detection threshold in neurons with relatively low basal enkephalin levels or alternatively, de novo enkephalin expression in neuron populations.

\section{Increased number of eGFP-positive neurons in partial sciatic nerve ligations}

Met-enkephalin immunoreactivity in the spinal cord dorsal horn increases after sciatic nerve ligation [18]. To confirm whether our BAC transgenic mouse is useful for analyzing the effect of sciatic nerve ligation on enkephalin expression, the number of eGFP-positive neurons on the sciatic nerve-ligated (ipsilateral) side was compared with the number on the nonligated (contralateral) side in spinal sections. The number of eGFP-positive neurons significantly increased in ipsilateral compared with contralateral [ipsilateral, $66.06 \pm 2.42$ ( $\mathrm{n}=18$ ); contralateral, $58.00 \pm 1.55(\mathrm{n}=18) ; P<0.01$; Figure 3]. This result is consistent with a previous report [18].

Reverse-transcription polymerase chain reaction (RT-PCR) analysis of the expression of glutamate decarboxylase 67 and $5-\mathrm{HT}_{3}$ receptor mRNAs in eGFP-positive neurons PCR products of glutamate decarboxylase 67 (GAD67) and $5-\mathrm{HT}_{3}$ receptor were detected in eGFP-positive 


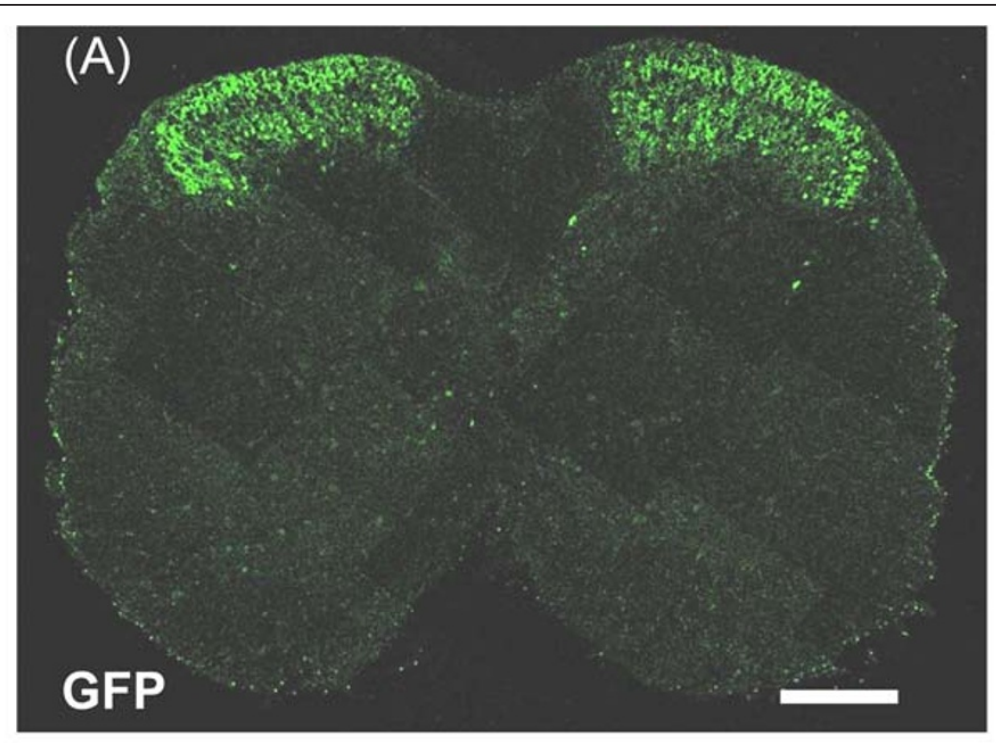

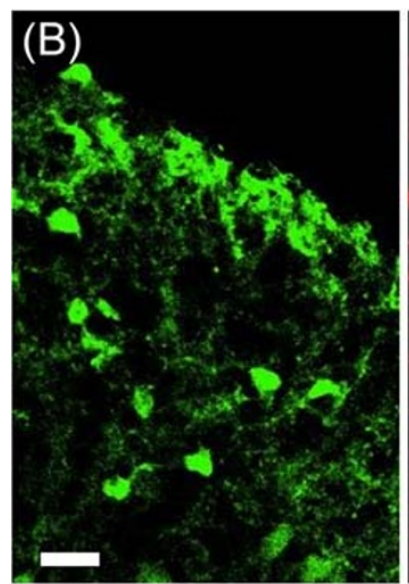

Anti-GFP

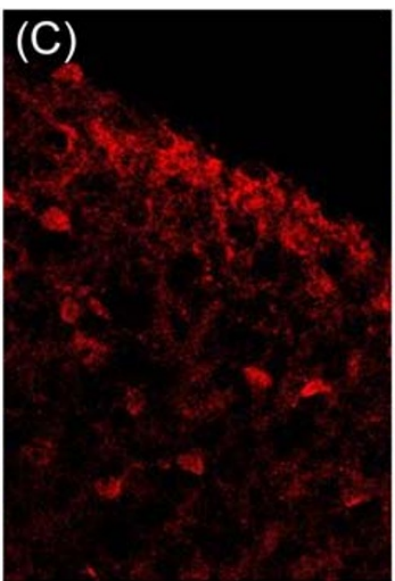

Anti-Enkephalin

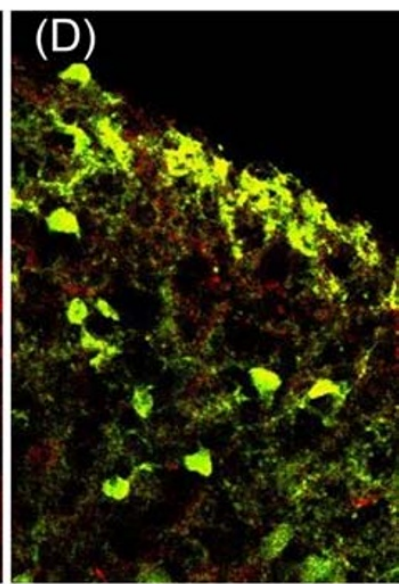

merge

Figure 1 Distribution of eGFP-positive neurons and double-staining IHC colocalization of eGFP expression with endogenous enkephalin. (A) Low magnification of the L4 segment of the spinal cord shows the highest density of eGFP-positive somata and fibers in SDH.

(B)-(D) Identification of eGFP-expressing neurons as enkephalinergic by double-staining IHC analysis with anti-eGFP (B, green) and anti-enkephalin (C, red) in SDH of penk1-eGFP BAC transgenic mouse. Scale bar $=200 \mu \mathrm{m}$ in (A), $20 \mu \mathrm{m}$ in (B)-(D).

neurons in SDH (Figure 4). The results of single-neuron RT-PCR indicated that GAD67 (detected in 15/15 eGFP-positive neurons, $100.0 \%$ ) and $5-\mathrm{HT}_{3}$ receptors (detected in 6/27 eGFP-positive neurons, 22.2\%) were co-expressed in the somatodendritic regions of the enkephalinergic neurons in SDH.

\section{Discussion}

Distribution of enkephalinergic neurons in SDH

We visualized presumptive enkephalinergic neurons in the spinal cord sections by generating a BAC transgenic mouse in which eGFP is expressed in enkephalinergic neurons under the control of the penk1 promoter.
Immunohistochemical investigations showed that enkephalinergic neurons were located in the dorsal horn of the spinal cord, with the highest density in the superficial laminae, thus suggesting eGFP-positive neurons are enkephalinergic. This distribution in the mouse model is similar to that described previously in rat and cat models $[3,8]$.

\section{Co-expression of enkephalin, GAD67, and $5-\mathrm{HT}_{3}$ receptor} mRNAs in interneurons in SDH

Single-neuron RT-PCR analysis showed that most eGFPpositive neurons expressed GAD67 mRNAs and that some expressed $5-\mathrm{HT}_{3}$ receptor mRNAs. We previously 

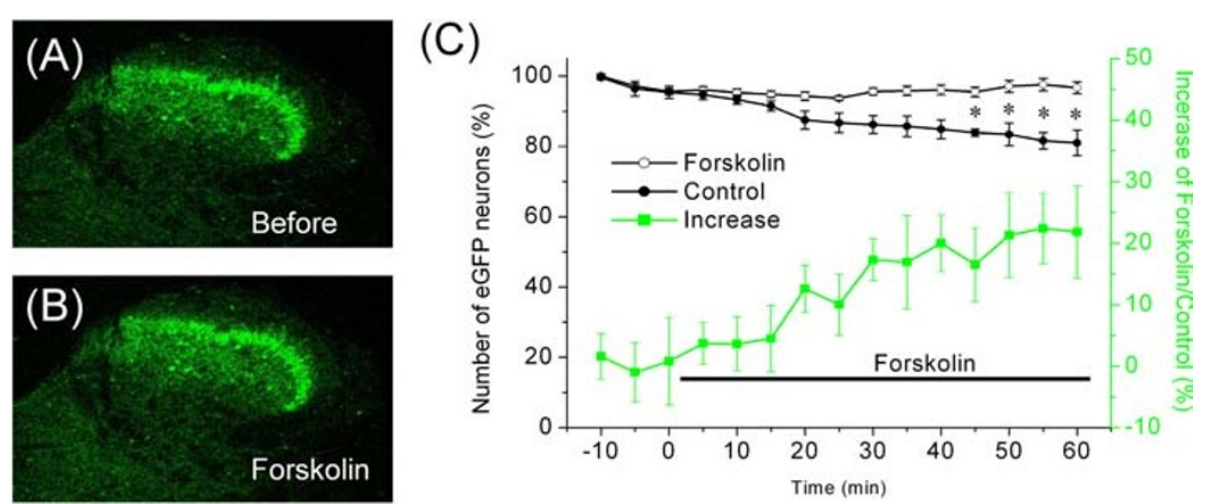

Figure 2 Effect of forskolin on the number of eGFP-positive neurons. (A, B) Representative images of eGFP fluorescence in the dorsal horn before $(A)$ and after (B) treatment with forskolin. (C) Forskolin $(5 \mu \mathrm{M})$ was applied as indicated by the horizontal bar. Data points on the graph (open circles and filled circles) indicate percentage of the number of eGFP-positive neurons normalized to the first ones at 10 minutes before forskolin treatment. Open circles and filled circles indicate the mean percentage of the number of eGFP-positive neurons with forskolin treatment $(n=7)$ and control neurons $(n=7)$, respectively. Filled squares indicate percent increases in the ratio of the number of eGFP-positive neurons with forskolin treatment to the number of control neurons. ${ }^{*} P<0.05$ indicates a significant difference between the forskolin treatment and the control neurons.

reported that enkephalinergic neurons express $5-\mathrm{HT}_{3}$ receptors in $\mathrm{SDH}[10]$ and that activation of $5-\mathrm{HT}_{3}$ receptors facilitates GABA release from some interneurons in SDH [14]. These results support the hypothesis that the release of enkephalin or the release of both

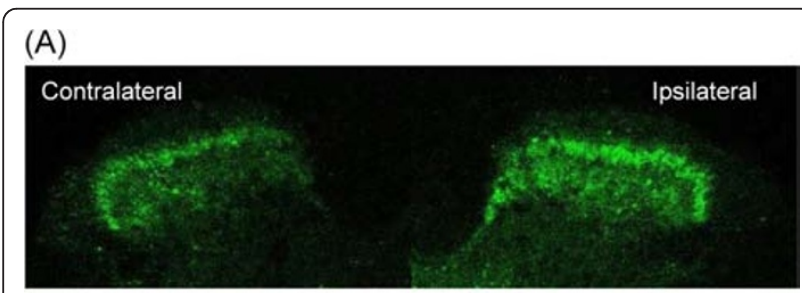

(B)

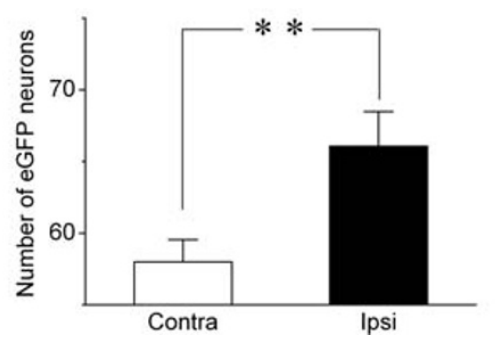

Figure 3 Sciatic nerve ligation increased the number of eGFPpositive neurons. (A) Representative image of eGFP fluorescence in SDH. eGFP fluorescence intensity was higher on the side ipsilateral (the right side of the figure) to sciatic nerve ligation 2 weeks after surgery compared with the contralateral (the left side). (B) Summary of the effect of nerve ligation on the number of eGFP-positive neurons. The number was the total of eGFP-positive neurons in an area of the SDH in an image scanned from a randomly selected section. Open bar indicates the side contralateral to ligation $(n=$ 18); filled bar indicates the ipsilateral side $(\mathrm{n}=18) .{ }^{* *} P<0.01$, significant. enkephalin and GABA from some eGFP-positive neurons is facilitated by activation of $5-\mathrm{HT}_{3}$ receptors.

\section{Changes in enkephalin expression induced by various} treatments as models of chronic pain in the spinal cord Analyses of the expression of enkephalin in the spinal cord during chronic inflammation have been previously reported in a number of models. Increases in PPE mRNA-labeled neurons in SDH have been reported in a number of injury model studies, including intraspinal microinjection of quisqualic acid to induce excitotoxic spinal cord injury [19], intraplantar injection of lambda

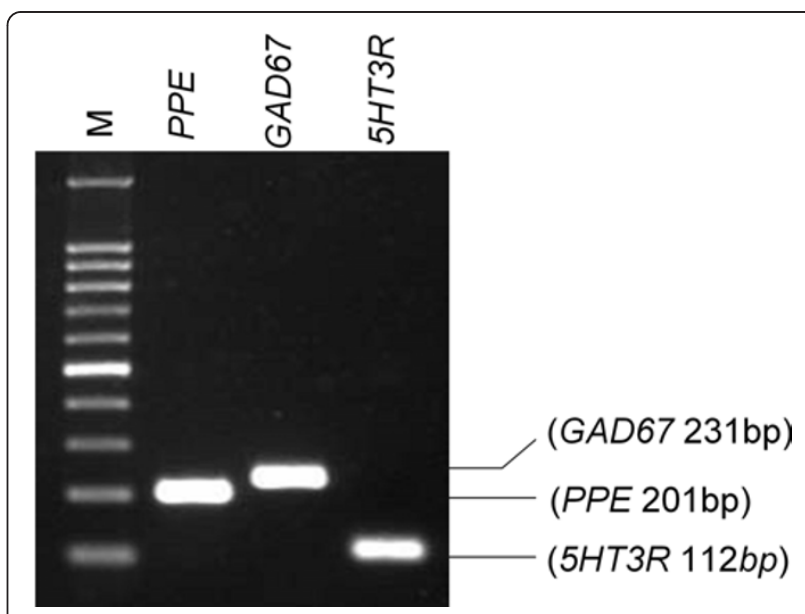

Figure 4 Co-expression of PPE, GAD67 and $5-\mathrm{HT}_{3}$ receptor mRNAs in an eGFP-positive neuron. A neuron was subjected to RT-PCR detection of GAD67 and 5- $\mathrm{HT}_{3}$ receptor mRNAs. Lane M shows a 100-bp DNA ladder. Values in parentheses indicate the expected lengths of the PCR products for NSE and GAD67, 5HT3R, respectively. 
carrageenan to induce hindpaw inflammation [24,25], and intradermal injection of heat-killed Mycobacterium butyricum to induce adjuvant arthritis [20]. In contrast to these inflammatory forms of chronic pain induced by various injections, there was no significant change in the spinal cord expression of enkephalin after sciatic nerve crush $[18,26]$ or after complete transection of the sciatic nerve [25].

The impact of CCI, which produces a painful neuropathy of the sciatic nerve, is less clear. Quantification of immunohistochemical staining in the spinal cord dorsal horn showed an increase in Met-enkephalin $[18,26]$. On the other hand, no significant alteration in the level of PPE mRNA was detected by RNA blot analysis after CCI [25]. These reports suggest that even in the same chronic pain model, detection of enkephalin expression levels depend on the method of analysis used. Finally, in contrast to the results we report here, partial ligation of the sciatic nerve has been reported to produce a nonsignificant but moderate increase in enkephalin mRNA expression, as detected by in situ hybridization [27]. A possible explanation for these conflicting results is that the transgenic eGFP approach taken in our study is more sensitive than the in situ hybridization method.

\section{Possible causes for increased number of eGFP-positive neuron observed in sciatic nerve ligation or forskolin treatment}

There are the two explanations for the increased number of eGFP-positive neurons: elevated expression of eGFP (and presumably enkephalin) above the detection threshold or new expression of eGFP (and presumably enkephalin) in populations that were previously eGFPnegative. The increased number of eGFP-positive neurons by sciatic nerve ligation or forskolin treatment may have resulted from both mechanisms, but in either case, it is impossible to determine which mechanism in this study. While our data does not provide direct evidence of a linear and homogeneous relationship between increased eGFP and enkephalin, this issue might be addressed in a comparison of the intensity of eGFP signal in neurons with low versus high enkephalin levels. If the comparison shows a precise relationship between increased eGFP and enkephalin, it might be possible to quantify how many treatments increase the number of enkephalinergic neurons and how much the expression level of enkephalin in each cell is increased.

\section{Other eGFP-transgenics used as tools in spinal dorsal cord studies}

Figure 1 shows a dense distribution of eGFP-positive neurons in SDH. GABA-like immunoreactivity is present in $70 \%$ of met-enkephalin-positive neurons located in laminae II and III [13]. In transgenic mice expressing
eGFP in GABAergic neurons under the control of the GAD67 gene (GAD1) promoter, almost every eGFPlabeled neuron in lamina II is GABAergic [28]. In addition, more than $80 \%$ of spinal neurons expressing GFP under the control of the prion promoter show GABAlike immunoreactivity [29]. Our RT-PCR analysis showed that almost all eGFP-positive neurons also express GAD67 (Figure 4). These data suggest that a subpopulation of eGFP-positive neurons in our study contains GABA in SDH.

Zeilhofer et al. generated BAC transgenic mice that express eGFP specifically in glycinergic neurons under the control of the glycine transporter GlyT2 promoter [30]. The BAC transgenic mice were used to measure the change in the number of spinal glycinergic neurons in CCI model of neuropathic pain [31]. The report suggests that loss of glycinergic neurons is not necessary for the development of pathological nociceptive behavior in the CCI model. GABAergic neurons containing enkephalin do not show glycine-like immunoreactivity [13]. The mechanism underlying the loss of spinal GABAergic neurons in neuropathic pain is still controversial, but this may be due to a combination of loss of neurons coexpressing GABA and glycine, and an increase in neurons coexpressing GABA and enkephalin.

\section{Conclusion}

In conclusion, we generated BAC transgenic mice expressing eGFP in enkephalinergic neurons. These mice appear to be a feasible option for identifying enkephalinergic neurons under in vitro conditions in animal models of persistent pain (i.e., forskolin and sciatic nerve ligation). In addition, if eGFP is shown to have a linear relationship with enkephalin levels, this transgenic mouse may prove useful as an assay of enkephalin expression levels under various conditions both in vitro and in vivo. The physiological characterization of SDH neurons identified as enkephalinergic neurons would help elucidate the neuronal mechanisms underlying nociceptive modulation in the spinal dorsal horn.

\section{Methods}

\section{Generation of penk1-eGFP BAC transgenic mice}

To visualize enkephalin-containing neurons, we generated BAC transgenic mice expressing eGFP in enkephalinergic neurons under the control of the penk1 promoter. A BAC containing the penk1 gene was used to generate penk1-eGFP BAC transgenic mice. The eGFP gene was inserted after the ATG start codon of the penk1 gene. Transgenic mice expressing eGFP under the control of a BAC DNA containing the enkephalin gene were produced. BAC in Escherichia coli (E. coli) were modified based on a protocol developed by Yang et al. [32]. In the targeting construct, the eGFP cDNA 
was inserted in front of the stop codon of the penk1 gene, generating a $\mathrm{C}$-terminal fusion protein. The recombinant cassette was introduced into pBluescript II KS (Stratagene), which contained the open reading frame of the eGFP gene. Fragment A (FA) consisted of $50 \mathrm{bp}$ prior to the ATG site of the PPE gene, and fragment $\mathrm{B}$ (FB) consisted of 50 bp subsequent to exon 1 of the gene. pBluescript II KS-FA-eGFP-FB was transformed into DH10B E. coli containing BAC clone RP23365K8 (Invitrogen, Carlsbad, CA, USA). Modified BAC clones were produced by two homologous recombinations in E. coli and confirmed by PCR analysis. The BAC DNA was prepared using a Nucleobond BAC 100 kit (Macherey-Nagel, Düren, Germany) and was linearized. Subsequently, the linearized DNA was run on a pulsed-field gel and purified from the gel with GenePure LE agarose (BM, Tokyo, Japan). The linearized BAC DNA was injected into pronuclei of C57BL/6 mouse zygotes. Genomic DNAs of founder mice were collected from their tail blood. The founder mice were screened by PCR for the presence of the eGFP gene and 5'- and 3'-ends of the linearized BAC DNA with primers 5'GACACGCTGAACTTGTGG-3' and 5'CTGGTCCTGATCCACGAC-3'. The founder mice were bred with wild-type C57BL/6 mice (Japan SLC, Shizuoka, Japan), F1 mice were subsequently crossed with each other, and then transgenic lines were maintained by sibling mating. In this study, these transgenic mice are referred to as penk1-eGFP BAC transgenic mice.

All animal experiments were approved by the institutional animal care and use committees at the Dokkyo Medical University. The care and use of the animals were in accordance with the National Institutes of Health guidelines on animal care and the guidelines of the International Association for the Study of Pain [33].

\section{Preparation of spinal cord sections}

Animals aged 6-8 weeks were intraperitoneally anesthetized with pentobarbital $(50 \mathrm{mg} / \mathrm{kg})$ and segments of the spinal cord at the lumbosacral (L4-S1) level were removed. A microslicer (Dosaka EM, Osaka, Japan) was used to cut transverse sections in ice-cold modified Krebs solution [equilibrated with $95 \% \mathrm{O}_{2}-5 \% \mathrm{CO}_{2}$, containing (in mM) 212 sucrose, $3 \mathrm{KCl}, 25 \mathrm{NaHCO}_{3}, 1$ $\mathrm{NaH}_{2} \mathrm{PO}_{4}, 2 \mathrm{CaCl}_{2}, 1 \mathrm{MgSO}_{4}$, and $11 \mathrm{D}$-glucose; $\mathrm{pH}$ 7.4]. The thickness of the sections was $350-450 \mu \mathrm{m}$ for the measurement of fluorescence intensity of eGFP and $500 \mu \mathrm{m}$ for the immunohistochemistry experiments.

\section{Immunohistochemical study}

Transverse sections $500-\mu \mathrm{m}$-thick were stored in modified Krebs solution containing colchicine $(10 \mu \mathrm{g} / \mathrm{mL}$; Sigma, St. Louis, MO, USA) for $6 \mathrm{~h}$ at room temperature. Colchicine, an axonal transport blocking agent, was used to enhance the signal-to-background ratio and to clearly show the colocalization of endogenous PPE and eGFP in SDH neurons. The sections were cryoprotected in $30 \%$ sucrose/PBS overnight at $4^{\circ} \mathrm{C}$. Cryosections of $20 \mu \mathrm{m}$ thickness were prepared using a cryostat, and then blocked with 5\% normal goat serum in PBS containing $0.1 \%$ Triton X-100 for $1 \mathrm{~h}$ at room temperature. After blocking, sections were immunostained with blocking solution containing mouse monoclonal anti-Met- and Leu-enkephalin antibody (1:200; Millipore, Billerica, MA, USA) and rabbit polyclonal anti-eGFP antibody (1:500; MBL, Woburn, MA, USA) overnight at $4^{\circ} \mathrm{C}$. Sections were washed with PBS and then incubated with DyLight 488-labeled goat anti-rabbit IgG for anti-eGFP antibody and DyLight 549-labeled goat antimouse IgG (1:1000; KPL, Gaithersburg, MD, USA) for anti-enkephalin antibody for $1 \mathrm{~h}$ at room temperature. Sections were rinsed in PBS, mounted in Fluoromount (Diagnostic BioSystems, Pleasanton, CA, USA) and coverslipped. Sections were observed using a confocal laser scanning microscope (FluoView FV500; Olympus, Tokyo, Japan). The numbers of neurons immunolabeled with both anti-enkephalin and anti-eGFP as well as with antieGFP alone were counted.

\section{Measurement of eGFP-positive neurons in sections treated with forskolin}

For these experiments and for single-neuron RT-PCR experiments, we used a fixed-stage upright microscope equipped with a confocal laser scanning system. Spinal sections were perfused with Krebs solution containing forskolin (an activator of AC; Sigma; $5 \mu \mathrm{M}$ ). To record the time course of eGFP fluorescence intensity, images were obtained every $5 \mathrm{~min}$ in the confocal laser scanning microscope. The percent increase was estimated by dividing the number of eGFP-positive neurons with forskolin treatment by the number of control neurons without forskolin treatment at the same time point.

\section{Partial ligation of the sciatic nerve}

Partial ligation of the sciatic nerve was performed in penk1-eGFP BAC transgenic mice aged 7-9 weeks. The mice were kept at controlled room temperature under a $12 \mathrm{~h}$ light:dark cycle. They were anesthetized by intraperitoneal injection of sodium pentobarbital $(50 \mathrm{mg} / \mathrm{kg})$. The left sciatic nerve was partially ligated according to the protocol described by Seltzer et al. [34].

\section{Assessment of mechanical allodynia induced by partial ligation of the sciatic nerve}

Each mouse was placed in a clear plastic box (height, 15 $\mathrm{cm}$; diameter, $12 \mathrm{~cm}$ ) on an elevated metal mesh floor. The withdrawal threshold to mechanical stimulation was determined. A mechanical stimulus was applied from 
underneath the mesh floor to the plantar aspect of the foot using an Electro von Frey (Model 1601; IITC, Woodland Hills, CA, USA). The lowest strength from five tests that induced a withdrawal response was considered the withdrawal threshold. Measurements were obtained on individual mice every day from 3 days prior to surgery to 21 days after surgery.

\section{Single-neuron RT-PCR}

After incubation in modified Krebs solution for $1 \mathrm{~h}$ at $37^{\circ} \mathrm{C}$, spinal sections were mounted in a recording chamber on the stage of a fixed-stage upright microscope (BX50WI; Olympus) and continuously perfused with Krebs solution [equilibrated with $95 \% \mathrm{O}_{2}-5 \% \mathrm{CO}_{2}$, containing (in mM) $113 \mathrm{NaCl}, 3 \mathrm{KCl}, 25 \mathrm{NaHCO}_{3}, 1$ $\mathrm{NaH}_{2} \mathrm{PO}_{4}, 2 \mathrm{CaCl}_{2}, 1 \mathrm{MgCl}_{2}$, and 11 D-glucose; $\mathrm{pH}$ 7.4].

After eGFP-positive neurons were identified in $\mathrm{SDH}$ using a confocal laser scanning system (FluoView 300; Olympus), as previously described [16], neurons were aspirated into a pipette under infrared differential interference contrast (IR-DIC) optics, and a CCD video camera (IR-CCD 2400; Hamamatsu Photonics, Hamamatsu, Japan) [10]. The collecting pipette had a tip diameter of approximately $3.5 \mu \mathrm{m}$ and contained $2 \mu \mathrm{L}$ of $\mathrm{Ca}^{2+}$-free and $\mathrm{Mg}^{2+}$-free PBS. The neurons were then injected into thin-walled autoclaved PCR tubes under gentle positive pressure and immediately frozen and stored at $-80^{\circ} \mathrm{C}$ until use. The PCR tubes contained $2 \mu \mathrm{L} \mathrm{MgCl}_{2}$ (25 mM), $2 \mu \mathrm{L} 10 \times$ PCR buffer, $0.5 \mu \mathrm{L}$ RNase inhibitor (40,000 units/mL), $2 \mu \mathrm{L}$ nonionic detergent IGEPAL CA-630 (5\%), and $5 \mu \mathrm{L}$ diethylpyrocarbonate-treated water. On the following day, lysis was performed using IGEPAL CA-630 at room temperature for $5 \mathrm{~min}$; the reverse transcription (RT) mixture, containing $1 \mu \mathrm{L}$ oligo primers $(0.5 \mu \mathrm{g} / \mathrm{L}), 2 \mu \mathrm{L}$ mixed deoxynucleotide triphosphates (dNTPs, $10 \mathrm{mM}), 2 \mu \mathrm{L}$ dithiothreitol $(0.1$ M), $0.5 \mu \mathrm{L}$ RNase inhibitor (40,000 units $/ \mathrm{mL})$, and $1 \mu \mathrm{L}$ SuperScript II RT (200 units/ $\mu \mathrm{L}$ ), was then added. The reaction mixture was incubated at $42^{\circ} \mathrm{C}$ for $50 \mathrm{~min}$ and subsequently heat-inactivated at $70^{\circ} \mathrm{C}$ for $15 \mathrm{~min}$. The total volume of $20 \mu \mathrm{L}$ complementary DNA (cDNA) was stored at $-20^{\circ} \mathrm{C}$. PCRs were performed in $50 \mu \mathrm{L}$ of solution containing $20 \mathrm{mM}$ Tris- $\mathrm{HCl}, 50 \mathrm{mM} \mathrm{KCl}, 2.5$ $\mathrm{mM} \mathrm{MgCl} 2,0.2 \mathrm{mM}$ dNTPs, and 2.5 units of Taq DNA polymerase. The concentration of primers was $20 \mathrm{nM}$ in the first PCR and $200 \mathrm{nM}$ in the second PCR. The primers targeted five genes: neuron-specific enolase (NSE), PPE, GAD67, 5- $\mathrm{HT}_{3}$ receptor, and eGFP. The primer sequences and product lengths are listed in Table 1.

The amount of cDNA used for the first PCR varied from 3 to $7 \mu \mathrm{L}$ and $1 \mu \mathrm{L}$ of the first PCR product was used for the second PCR. A thermal cycler (GeneAmp 2400; Perkin Elmer, Waltham, MA, USA) was programmed for 35-40 cycles of 1 min of denaturation $\left(94^{\circ} \mathrm{C}\right), 1 \mathrm{~min}$ of annealing $\left(54-59^{\circ} \mathrm{C}\right)$, and $1 \mathrm{~min}$ of elongation $\left(72^{\circ} \mathrm{C}\right)$. The second PCR products were visualized by electrophoresis on $2 \%$ agarose gel with ethidium bromide staining. All products were sequenced with dye terminator chemistry (Applied Biosystems, Foster City, CA, USA) and a DNA sequencer (Model 377; Applied Biosystems), and matched the published sequences. All reagents for the RT-PCR procedure, except the RNase inhibitor (Toyobo, Osaka, Japan) and IGEPAL CA-630 (Sigma), were obtained from Gibco/Invitrogen (Carlsbad, CA, USA).

\section{Statistical analysis}

Data are presented as mean \pm SE unless otherwise stated. Effects of sciatic nerve ligation on the number of eGFP-positive neurons were compared using a paired $t$ test. In addition, Student's $t$-test was used when appropriate. The data for the forskolin experiment were statistically analyzed by two-way analysis of variance (ANOVA), followed by post hoc multiple comparison (Tukey's test). $P<0.05$ was considered significant.

\section{List of Abbreviations}

5-HT: 5-hydroxytryptamine; $\mathbf{5}-\mathbf{H T}_{\mathbf{3}}$ : 5-HT type 3; AC: Adenylate Cyclase; BAC: Bacterial Artificial Chromosome; $\mathbf{C C l}$ : Chronic constriction injury; $\mathbf{C A M P \text { : }}$

Table 1 Primers used for single-neuron reverse transcription-polymerase chain reaction (RT-PCR)

\begin{tabular}{llllll}
\hline Gene & Name & Primer Sequences & Sequence Start & Product Length, bp & GenBank Accession Number \\
\hline PPE & PPE-F & 5'-CTACAGGCGCGTTCTTCTCT-3' & 273 & 201 & NM_001002927 \\
& PPE-R & 5'-AGCAGCAAACAGGATGA-3' & 561 & & NM_008077 \\
GAD67 & GAD67-F & 5'-CAAGTTCTGGCTGATGTGGA-3' & 1616 & 231 & \\
& GAD67-R & 5'-GCCACCCTGTGTAGCTTTC-3' & 1846 & 112 & NM_013561 \\
5HT3R & 5HT3-F & 5'-CGTCAAGTCTGGTTCCTTACC-3' & 1794 & & \\
& 5HT3-R & 5'-GCATCTATGCAAGATGATTTGC-3 & 1905 & & \\
\hline
\end{tabular}

$P P E$, preproenkephalin; GAD67, glutamate decarboxylase 67 gene; $5 H T 3 R$, 5-hydroxytryptamine (5-HT, serotonin) type 3 receptor gene. Two 5-HT 3 receptor subunits were cloned, namely subunit $\mathrm{A}\left(5-\mathrm{HT}_{3 \mathrm{~A}}\right)$ and subunit $\mathrm{B}\left(5-\mathrm{HT}_{3 \mathrm{~B}}\right)$. Although expression of $5-\mathrm{HT}_{3 \mathrm{~A}}$ subunits alone yields functional $5-\mathrm{HT} \mathrm{T}_{3}$ receptors, it has been suggested that $5-\mathrm{HT}_{3 B}$ subunits modify the physiological and pharmacological properties of $5-\mathrm{HT}_{3}$ receptors $[35,36]$. In this study we attempted to detect the $5-\mathrm{HT}_{3 \mathrm{~A}}$ subunits. The primers were used for both the first and the second PCR amplification. 
cyclic-AMP; eGFP: Enhanced Green Fluorescent Protein; GABA: $\gamma$ aminobutyric acid; GAD67: Glutamate Decarboxylase 67; GFP: Green Fluorescence Protein; NSE: Neuron-Specific Enolase; PPE: Preproenkephalin; penk1: PPE gene; RT-PCR: Reverse-Transcription Polymerase Chain Reaction; SDH: Superficial Dorsal Horn;

\section{Acknowledgements}

We would like to thank S Tanaka for RT-PCR analysis and partial ligation of the sciatic nerve.

\section{Author details}

'Department of Physiology and Biological Information, Dokkyo Medical University, School of Medicine, Kitakobayashi 880, Mibu, Tochigi 321-0293, Japan. ${ }^{2}$ Radioisotope Laboratory, Kyorin University, School of Medicine, 6-202, Shinkawa, Mitaka, Tokyo 181-8611, Japan.

\section{Authors' contributions}

$\mathrm{YH}, \mathrm{TF}$ and TK participated in the preparation of this manuscript and approved the final version of the manuscript. The individual contributions of the four authors to the manuscript are as given below. TF took the photographs and counted the number of eGFP-positive neurons on sections after the treatments. MT generated the BAC transgenic mice. TK carried out the immunohistochemical study. YH conceived the study and coordinated all experiments.

Received: 18 October 2010 Accepted: 7 May 2011

Published: 7 May 2011

\section{References}

1. Bennett GJ, Ruda MA, Gobel S, Dubner R: Enkephalin immunoreactive stalked neurons and lamina Ilb islet neurons in cat substantia gelatinosa. Brain Res 1982, 240:162-166.

2. Glazer EJ, Basbaum Al: Immunohistochemical localization of leucineenkephalin in the spinal cord of the cat: enkephalin-containing marginal neurons and pain modulation. J Comp Neurol 1981, 196:377-389.

3. Hökfelt T, Elde R, Johansson O, Terenius L, Stein L: The distribution of enkephalin-immunoreactive neuron bodies in the rat central nervous system. Neurosci Lett 1977, 5:25-31.

4. Basbaum Al, Fields HL: Endogenous pain control systems: brainstem spinal pathways and endorphin circuitry. Annu Rev Neurosci 1984, 7:309-338.

5. Giordano J: Analgesic profile of centrally administered 2-methylserotonin against acute pain in rats. Eur J Pharmacol 1991, 199:233-236.

6. Yang SW, Zhang ZH, Wang R, Xie YF, Qiao JT, Dafny N: Norepinephrine and serotonin-induced antinociception are blocked by naloxone with different dosages. Brain Res Bull 1994, 35:113-117.

7. López JF, Chalmers DT, Vázquez DM, Watson SJ, Akil H: Serotonin transporter mRNA in rat brain is regulated by classical antidepressants. Biol Psychiatry 1994, 35:287-290.

8. Glazer EJ, Basbaum Al: Axons which take up $\left[{ }^{3} \mathrm{H}\right]$ serotonin are presynaptic to enkephalin immunoreactive neurons in cat dorsal horn. Brain Res 1984, 298:386-391.

9. Miletic V, Hoffert MJ, Ruda MA, Dubner R, Shigenaga Y: Serotoninergic axonal contacts on identified cat spinal dorsal horn neurons and their correlation with nucleus raphe magnus stimulation. J Comp Neurol 1984, 228:129-141.

10. Tsuchiya $M$, Yamazaki $H$, Hori $Y$ : Enkephalinergic neurons express $5-H_{3}$ receptors in the spinal cord dorsal horn: single cell RT-PCR analysis. Neuroreport 1999, 10:2749-2753.

11. Huang J, Wang YY, Wang W, Li YQ, Tamamaki N, Wu SX: 5-HT 3 A receptor subunit is expressed in a subpopulation of GABAergic and enkephalinergic neurons in the mouse dorsal spinal cord. Neurosci Lett 2008, 441:1-6.

12. Jo YH, Stoeckel ME, Schlichter R: Electrophysiological properties of cultured neonatal rat dorsal horn neurons containing GABA and metenkephalin-like immunoreactivity. J Neurophysiol 1998, 79:1583-1586.

13. Todd AJ, Spike RC, Russell G, Johnston HM: Immunohistochemical evidence that Met-enkephalin and GABA coexist in some neurones in rat dorsal horn. Brain Res 1992, 584:149-156

14. Fukushima T, Ohtsubo T, Tsuda M, Yanagawa Y, Hori Y: Facilitatory actions of serotonin type 3 receptors on GABAergic inhibitory synaptic transmission in the spinal superficial dorsal horn. J Neurophysiol 2009, 102:1459-1471.

15. Dobi AL, Palkovits M, Palkovits CG, Santha E, van Agoston DL: Protein-DNA interactions during phenotypic differentiation. Mol Neurobiol 1995, 10:185-203.

16. Fukushima T, Tomitori H, Iwata H, Maekawa M, Hori Y: Differential expression of NMDA receptor subunits between neurons containing and not containing enkephalin in the mouse embryo spinal cord. Neurosc Lett 2005, 391:11-16.

17. Dubner R, Ruda MA: Activity-dependent neuronal plasticity following tissue injury and inflammation. Trends Neurosci 1992, 15:96-103.

18. Sommer C, Myers RR: Neurotransmitters in the spinal cord dorsal horn in a model of painful neuropathy and in nerve crush. Acta Neuropathol 1995, 90:478-485.

19. Abraham KE, Brewer KL, McGinty JF: Opioid peptide messenger RNA expression is increased at spinal and supraspinal levels following excitotoxic spinal cord injury. Neuroscience 2000, 99:189-197.

20. Calzá L, Pozza M, Zanni M, Manzini CU, Manzini E, Hökfelt T: Peptide plasticity in primary sensory neurons and spinal cord during adjuvantinduced arthritis in the rat: an immunocytochemical and in situ hybridization study. Neuroscience 1998, 82:575-589.

21. Nishimori T, Buzzi MG, Moskowitz MA, Uhl GR: Preproenkephalin mRNA expression in nucleus caudalis neurons is enhanced by trigeminal stimulation. Brain Res Mol Brain Res 1989, 6:203-210.

22. Simantov R, Kuhar MJ, Uhl GR, Snyder SH: Opioid peptide enkephalin: immunohistochemical mapping in rat central nervous system. Proc Nat/ Acad Sci USA 1977, 74:2167-2171.

23. Agoston DV, Santha E, Shieh G, Lala R, Dobi A: Isolation and structural and genetic analysis of the mouse enkephalin gene and its $d(A C / T G) n$ repeats. DNA Seq 1998, 9:217-226.

24. Noguchi K, Dubner R, Ruda MA: Preproenkephalin mRNA in spinal dorsal horn neurons is induced by peripheral inflammation and is co-localized with Fos and Fos-related proteins. Neuroscience 1992, 46:561-570.

25. Draisci G, Kajander KC, Dubner R, Bennett GJ, ladarola MJ: Up-regulation of opioid gene expression in spinal cord evoked by experimental nerve injuries and inflammation. Brain Res 1991, 560:186-192.

26. George A, Marziniak M, Schafers M, Toyka KV, Sommer C: Thalidomide treatment in chronic constrictive neuropathy decreases endoneurial tumor necrosis factor-alpha, increases interleukin-10 and has long-term effects on spinal cord dorsal horn met-enkephalin. Pain 2000, 88:267-275.

27. Delander GE, Schott E, Brodin E, Fredholm BB: Spinal expression of mRNA for immediate early genes in a model of chronic pain. Acta Physiol Scand 1997, 161:517-525.

28. Heinke B, Ruscheweyh R, Forsthuber L, Wunderbaldinger G, Sandkühler J: Physiological, neurochemical and morphological properties of a subgroup of GABAergic spinal lamina II neurones identified by expression of green fluorescent protein in mice. J Physiol 2004, 560:249-266

29. Hantman AW, van den Pol AN, Perl ER: Morphological and physiological features of a set of spinal substantia gelatinosa neurons defined by green fluorescent protein expression. J Neurosci 2004, 24:836-842.

30. Zeilhofer HU, Studler B, Arabadzisz D, Schweizer C, Ahmadi S, Layh B, Bösl MR, Fritschy JM: Glycinergic neurons expressing enhanced green fluorescent protein in bacterial artificial chromosome transgenic mice. J Comp Neurol 2005, 482:123-141.

31. Hermanns $H$, Muth-Selbach U, Lipfert P, Braun S, Werdehausen R, Bauer I: Loss of spinal glycinergic neurons is not necessary for development of neuropathic pain in transgenic mice expressing enhanced green fluorescent protein in glycinergic neurons. Neuroscience 2009, 159:1148-1153.

32. Yang XW, Model $P$, Heintz N: Homologous recombination based modification in Escherichia coli and germline transmission in transgenic mice of a bacterial artificial chromosome. Nat Biotechnol 1997, 15:859-865.

33. Zimmermann M: Ethical guidelines for investigations of experimental pain in conscious animals. Pain 1983, 16:109-110.

34. Seltzer Z, Dubner R, Shir $Y$ : A novel behavioral model of neuropathic pain disorders produced in rats by partial sciatic nerve injury. Pain 1990, 43:205-218.

35. Davies PA, Pistis M, Hanna MC, Peters JA, Lambert JJ, Hales TG, Kirkness EF: The $5-\mathrm{HT}_{3 \mathrm{~B}}$ subunit is a major determinant of serotonin-receptor function. Nature 1999, 397:359-363. 
36. Hapfelmeier G, Tredt C, Haseneder R, Zieglgänsberger W, Eisensamer B, Rupprecht R, Rammes G: Co-expression of the $5-\mathrm{HT}_{3 \mathrm{~B}}$ serotonin receptor subunit alters the biophysics of the $5-\mathrm{HT}_{3}$ receptor. Biophys J 2003, 84:1720-1733.

doi:10.1186/1471-2202-12-36

Cite this article as: Fukushima et al:: Physiological properties of enkephalin-containing neurons in the spinal dorsal horn visualized by expression of green fluorescent protein in BAC transgenic mice. BMC Neuroscience 2011 12:36.

Submit your next manuscript to BioMed Central and take full advantage of:

- Convenient online submission

- Thorough peer review

- No space constraints or color figure charges

- Immediate publication on acceptance

- Inclusion in PubMed, CAS, Scopus and Google Scholar

- Research which is freely available for redistribution 